\title{
ANALISA DEFORMASI UNTUK PREDIKSI SUMBER TEKANAN MAGMA MENGGUNAKAN DATA GPS (Studi Kasus: Gunung Merapi, Daerah Istimewa Yogyakarta)
}

\author{
Budi Joko Purnomo ${ }^{1}$, Ira Mutiara Anjasmara ${ }^{1}$, Nurnaning Aisyah ${ }^{2}$ \\ ${ }^{1}$ Jurusan Teknik Geomatika FTSP-ITS, Kampus ITS Sukolilo, Surabaya, 60111 \\ ${ }^{2}$ Balai Penyelidikan dan Pengembangan Teknologi Kebencanaan Geologi2), BPPTKG, Yogyakarta 55166 \\ Email : ira@geodesy.its.ac.id, aisyahnaning@gmail.com
}

\begin{abstract}
Abstrak
Gunung Merapi adalah salah satu gunungapi paling aktif di Indonesia yang terletak di Provinsi Daerah Istimewa Yogyakarta dan Jawa Tengah. Gunung Merapi memiliki periode letusan yang relative cepat yaitu sekitar 4 tahun sekali. Dengan aktivitas vulkanik yang tinggi dapat mengakibatkan perubahan deformasi pada tubuh Gunung Merapi pada bulan September 2013-Maret 2014.

Metode yang digunakan pada penelitian ini adalah metode deformasi dengan menggunakan alat ukur GPS. Karakteristik deformasi yang dikaji meliputi posisi, arah, dan besar pergeseran. Software yang digunakan adalah scientific software GAMIT. Untuk prediksi sumber tekanan mengggunakan model Mogi.

Dari hasil analisa yang dilakukan mulai bulan September 2013 sampai 31 Maret 2014, didapatkan nilai pergeseran horisontal untuk stasiun DELS sebesar 0.010801005 dan vertikal sebesar -0.02366 , pergeseran horisontal untuk stasiun GRWH sebesar 0.046374924 dan vertikal sebesar 0.04096, dan pergesreran horisontal untuk stasiun KLAT sebesar 0.013173629 dan vertikal sebesar -0.01479 . Nilai tersebut mengindikasikan bahwa tubuh gunung Merapi sedang mengalami deformasi dengan sifat deformasinya adalah inflasi. Sedangkan posisi pusat tekanan magma adalah $7^{\circ} 32^{\prime} 2.129^{\prime \prime}$ LS ; $110^{\circ} 26^{\prime} 51.57^{\prime}$ BT dengan kedalaman $\pm 7140.5084 \mathrm{~m}$ relatif dari puncak. Volume magma adalah $41788427.5957 \mathrm{~m}^{3}$ dan dapat digunakan untuk prediksi skala erupsi mendatang.
\end{abstract}

Kata Kunci: GPS, Deformasi, Inflasi, Pusat Tekanan Magma

\section{PENDAHULUAN}

\section{Latar Belakang}

Gunung Merapi adalah gunung termuda dalam rangkaian gunung berapi yang mengarah ke selatan dari Gunung Ungaran. Gunung ini terbentuk karena aktivitas di zona subduksi Lempeng Indo-Australia yang bergerak ke bawah Lempeng Eurasia menyebabkan munculnya aktivitas vulkanik di sepanjang bagian tengah Pulau Jawa. Puncak yang sekarang ini tidak ditumbuhi vegetasi karena aktivitas vulkanik tinggi. Puncak ini tumbuh di sisi barat daya puncak Gunung Batulawang yang lebih tua.

Metode pemantaun aktivitas gunung api yang telah diaplikasikan saat ini, yaitu antara lain metode seismik, metode visual, metode deformassi, metode kima gas, metode termal, metode gaya berat, metode geomagnetik, metode penginderaan jauh (Jamel, 2012). Metode deformasi banyak diaplikasikan dalam pemantaun gunung api dengan berbagai macam sensor dan sistem. Metode pemantauan deformasi umumnya menggunakan data terestris. Salah satunya menggunakan GPS. Gejala deformasi gunung api akan menyebabkan pergeseran posisi suatu titik tubuh dari gunung api. Pergeseran tersebut bisa terjadi baik secara horizontal maupun vertical (Bahlefi, 2013).

\section{METODOLOGI PENELITIAN}

\section{Lokasi Penelitian}

Lokasi penelitian terletakdi kawasan Gunung Merapi, Daerah Istimewa Yogjakarta dan Jawa Tengah. Area studi ini terletak di posisi geografis Lintang $7^{\circ} 32^{\prime} 5 " \mathrm{~S}$; Bujur $110^{\circ} 26^{\prime} 5^{\prime \prime} \mathrm{E}$. Lereng sisi selatan berada dalam 
administrasi Kabupaten Sleman, Daerah Istimewa Yogyakarta, dan sisanya berada dalam wilayah Provinsi Jawa Tengah, yaitu Kabupaten Magelang di sisi barat, Kabupaten Boyolali di sisi utara dan timur,serta Kabupaten Klaten di sisi tenggara. Gunung merapi memiliki ketinggian $2.968 \mathrm{~m} \mathrm{dpl}$, (per 2006) (BPPTKG, 2014).

\section{Data Dan Peralatan}

\section{Data}

Data yang digunakan dalam penelitian ini adalah:

1. Data RINEX

Data pengamatan GPS yang digunakan adalah data RINEX pada bulan September tahun 2013 sampai Maret tahun 2014. Data tersimpan setiap jam dalam format Rinex dengan sampling pengukuran tiap 1 detik. Data GPS bersumber dari hasil pemantauan online. Data pengamatan GPS diunduh di Balai Penyelidikan dan Pengembangan Teknologi Kebencanaan Geologi (BPPTKG) Yogyakarta. Data pengamatan yang digunakan adalah data pengamatan GPS BTK, GPS DELS, GPS GRWH,GPS KLAT.

Tabel 2.1 Lokasi data pengamatan GPS

\begin{tabular}{cll}
\hline NO & STASIUN & LOKASI \\
\hline 1 & BTK & $\begin{array}{l}\text { Kantor Pusat BPPTKG, } \\
\text { Yogyakarta }\end{array}$ \\
2 & DELS & Desa Deles, Klaten \\
3 & GRWH & Desa Grawah, Boyolali \\
4 & KLAT & Desa Klatakan, Magelang \\
\hline
\end{tabular}

2. Ada 3 file data tambahan yaitu : file gelombang pasang surut (otl_FES2004.grd), file atmosfer (atmdisp_YYYY), file pemodelan cuaca (vmf1grd.YYYY) dapat yang diunduh melalui

ftp://everest.mit.edu/pub/GRIDS/. Data sekunder yang dibutuhkan saat pengolahan akan diunduh otomatis oleh software GAMIT/GLOBK

\section{- Peralatan}

Peralatan yang digunakan dalam penelitian ini adalah:

1. Perangkat Keras (Hardware)
a. Stasiun GPS Online
b. Laptop

2. Perangkat Lunak (Software)
a. Sistem Operasi Linux Ubuntu 12.04
b. Leica Geo Office 8.1
c. Software GAMIT dan GLOBK
d. Software Generic Mapping Tools (GMT)

\section{Pengolahan Data}

Berikut penjelasan tahap pengolahan data:

1. Pengumpulan Data

Download data RINEX dari pusat data di kantor BPPTKG Yogyakarta.

2. Penggabungan data RINEX

Data RINEX yang diperoleh berupa data pengamatan per-jam, untuk mendapatkan data RINEX dalam 1 hari (Day of Year) maka dilakukan penggabungan menggunakan software LGO 8.1.

3. Pembuatan Direktori Kerja

4. Editing control files pada folder tables

5. Untuk menjalankan pengolahan GAMIT dengan automatic batch processing dengan menjalankan perintah berikut ini pada direktori kerja.

sh_gamit -s yyyy $\mathrm{ddd}_{1} \mathrm{ddd}_{2}$-expt <expt> -nogifs > sh_gamit.log \&

6. Editing file globk_comb.cmd dan glorg_comb.cmd.

7. Pengolahan menggunakan GLOBK

Selanjutnya menjalankan pengolahan GLOBK untuk menghasilkan kecepatan pergeseran secara time series.

sh_glred -s $\mathrm{YYYY}_{1} \mathrm{DDD}_{1} \mathrm{YYYY}_{2} \mathrm{DDD}_{2}$-expt NNNN -opt H G E

8. Deteksi data Outlier

Outliers adalah data yang menyimpang terlalu jauh dari data lainnya dalam suatu rangkaian data. Agar analisis dari hasil tidak menjadi bias atau tidak sesuai dengan sebenarnya, maka perlu dihilangkan.

9. Prediksi sumber tekanan.

Prediksi sumber tekanan magma menggunakan model MOGI. Pada tahap ini prediksi sumber tekanan magma 
menggunakan program MATLAB yang sudah ada.

\section{HASIL DAN PEMBAHASAN}

\section{Deteksi Outliers}

Outliers adalah data yang menyimpang terlalu jauh dari data lainnya dalam suatu rangkaian data. Adanya data outliers ini akan membuat analisis terhadap serangkaian data menjadi bias, atau tidak mencerminkan fenomena yang sebenarnya. Hasil plotting time series masih terdapat data outliers sehingga perlu dihilangkanData koordinat time series dapat dilihat pada file Val.[expt] dalam folder gsoln.

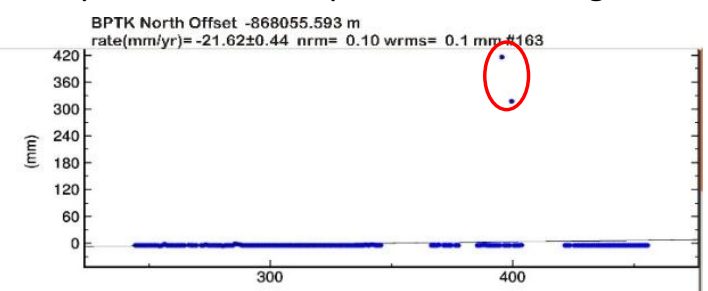

Gambar 1. contoh plottingtime series north stasiun BPTK yang belum dikurangi data outliers ,psbase_budi.BPTK.

\section{Kecepatan Vektor Pergeseran}

Kecepatan pergeseran adalah besaran yang menyatakan perubahan suatu titik pantau dalam selang waktu tertentu sehingga bisa menjadi indikator terjadinya deformasi di daerah pengamatan. Kecepatan pergeseran dapat di lihat pada plotting time series pada file psbase_[expt].[GPS] bagian rate (mm/yr).

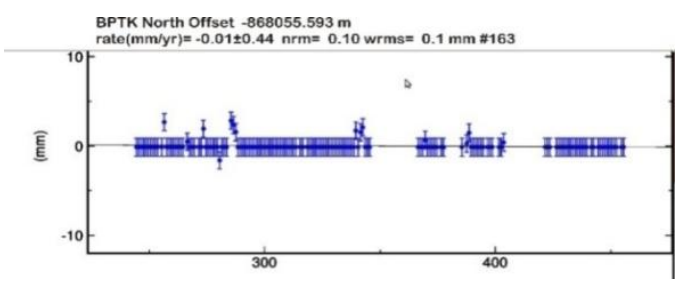

Gambar 2. contoh plottingtime series north stasiun BPTK yang sudah dikurangi data outliers ,psbase_budi.BPTK.

Tabel 1. Kecepatan pergeseran pengolahan dengan titik ikat BPTK.

\begin{tabular}{|c|c|c|c|c|}
\hline \multirow{2}{*}{ No. } & \multirow{2}{*}{ Site } & \multicolumn{3}{|c|}{ September $2013-$ Maret 2014} \\
\cline { 3 - 5 } & & $\begin{array}{c}\text { Ve } \\
(\mathrm{mm} / \mathrm{t} \text { ahun })\end{array}$ & $\begin{array}{c}\text { Vn } \\
(\mathrm{mm} / \mathrm{tahun})\end{array}$ & $\begin{array}{c}\text { Vu } \\
(\mathrm{mm} / \mathrm{t} \text { ahun })\end{array}$ \\
\hline 1 & DELS & $-5.39 \pm 0.77$ & $-9.36 \pm 0.77$ & $-23.66 \pm 7.60$ \\
\hline 2 & GRWH & $-24.20 \pm 1.12$ & $-39.56 \pm 1.12$ & $40.96 \pm 11.18$ \\
\hline 3 & KLAT & $-12.41 \pm 0.45$ & $-4.42 \pm 0.45$ & $-14.79 \pm 4.58$ \\
\hline
\end{tabular}

Arah dan kecepatan pergeseran horizontal terfokus pada jarak dari nilai pergeseran yang diolah. Nilai pergeseran tersebut dapat bernilai minus (-) atau plus (+) yang dapat mempengaruhi dari arah pergeseran. Berikut adalah gambar 3.4 mengenai penentuan arah dan kecepatan pergeseran dibagi dalam 4 kuadran (K) (Abidin, 2007).

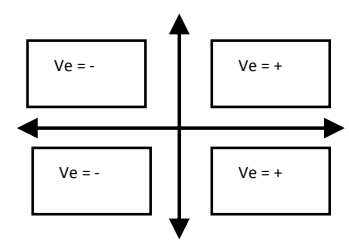

Gambar 3. Arah dan kecepatan pergeseran dalam kuadran.

Hasil plotting kecepatan pergeseran (velocity) menggunakan software MATLAB. Gambar 3.5 merupakan plotting kecepatan pergeseran (velocity) dari data pengamatan GPS DELS, GRWH, KLAT dengan titik ikat BPTK.

\section{Analisis Kecepatan Pergeseran}

Kecepatan vektor pergeseran yang telah dihitung selama satu tahun pengamatan perlu dilakukan uji statistik agar secara kualitatif mengindikasikan baik atau tidaknya hasil pengolahan. Uji statistik ini dilakukan dengan cara menguji variabel pergeseran titik (Pij) dari sesi pengamatan $i$ ke sesi $j$ yang nilainya dapat dihitung menggunakan rumus:

$$
P_{i j}=\sqrt{ }\left(d n_{i j}^{2}+d e_{i j}{ }^{2}\right)
$$

Adapun standar deviasi dihitung dengan menggunakan rumus :

$$
\text { Std } P_{i j}=\sqrt{ }\left(s d d n_{i j}^{2}+s d d e_{i j}\right)^{2}
$$

Hipotesis nol yang digunakan pada uji statistik ini adalah titik pengamatan tidak bergeser dalam selang $\mathrm{i}$ dan $\mathrm{j}$ sehingga :

Hipotesis nol

$$
\mathrm{HO}: \mathrm{P}_{\mathrm{ij}}=0
$$


Hipotesis Alternatif $\quad \mathrm{Ha}: \mathrm{P}_{\mathrm{ij}} \neq 0$

Statistik yang digunakan dalam menguji pergeseran titik-titik pengamatan adalah :

$$
T=P_{i j} / \operatorname{Std} P_{i j}
$$

Pergeseran dinyatakan signifikan atau hipotesis nol ditolak jika (Wolf, 2006):

$$
T>d f, \frac{\alpha}{2}
$$

Keterangan :

$\mathrm{P}_{\mathrm{ij}} \quad=$ Pergeseran titik pengamatan

Std $\mathrm{P}_{\mathrm{ij}}, \mathrm{Sd} \mathrm{dn}_{\mathrm{ij}}{ }^{2}, \mathrm{Sd} \mathrm{de}_{\mathrm{ij}}{ }^{2} \quad=$ Standar deviasi Pij, standar deviasi komponen $\mathrm{n}$ dan $\mathrm{e}$

$\mathrm{T}=$ Besaran yang menunjukkan signifikansi pergeseran

df =Derajat kebebasan

$\alpha \quad=$ Level signifikan yang digunakan

Digunakan tabel $t$-distribution dengan selang kepercayaan $95 \%$ sehingga nilai $\mathrm{T}>\mathrm{tdf}, \alpha / 2$ adalah 1,960 dimana menunjukkan terjadi pergeseran di semua stasiun pengamatan.

\section{Penentuan Posisi Tekanan Magma dan Volume Suplai Magma}

Pada sebagian besar gunug api yang ada di dunia, data-data deformasi memberikan nilai yang penting dalam meninjau aspek-aspek umum guna kepentingan prediksi letusan yang akan terjadi selanjutnya. Seorang ilmuwan Jepang bernama Kiyoo Mogi, melalui publikasinya di tahun 1958 menandai dimulainya era modern pada studi deformasi gunung berapi. Lewat model yang dikembangkannya (Mogi's model), deformasi yang diamati dapat terjadi di permukaan merupakan hasil dari adanya peningkatan tekanan (pressure) dari sebuah sumber kecil, spherical (bola) di dalam ruangan elastic tak berhingga yang berbentuk setengah ruang (half space) (Iguchi,2003).Pada penelitian tugas akhir ini dalam penentuan posisi tekanan magma menggunakan program pemodelan sumber tekanan magma pada MATLAB yang Reyzansza A.S(program MOGI) (Syahputr, 2014)

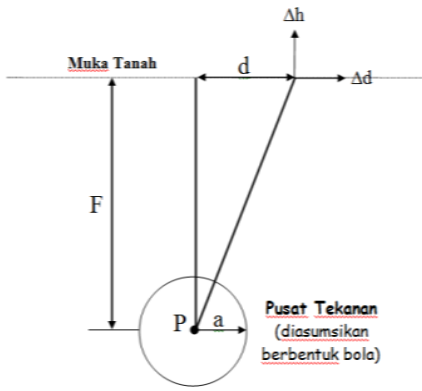

\section{Gambar 5. Model Mogi Untuk Penentuan Sumber} Tekanan Magma (Bahlefi, 2013)

Model Mogi secara umum ditunjukkan oleh gambaran dan formula berikut:

$$
\begin{aligned}
& \Delta d=\frac{a^{3} \Delta \mathrm{P}}{4 / 3 \mu} \frac{d}{\left(\mathbf{f}^{2}+d^{2}\right)^{\top 2}} \\
& \Delta h=\frac{a^{3} \Delta \mathrm{P}}{\mathrm{A} / 3 \mu} \frac{f}{\left.\mathbf{f}^{2}+d^{2}\right)^{\top 2}}
\end{aligned}
$$

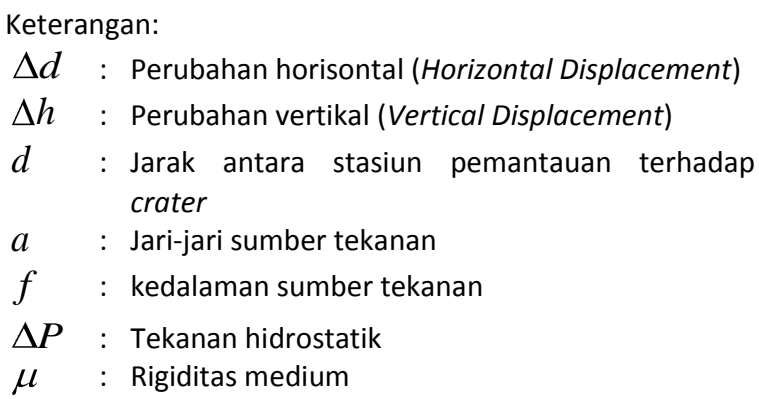

Metoda Grid Search digunakan untuk penentuan lokasi sumber tekanan, yaitu ditentukan pada saat diperoleh nilai residual terkecil antara pergeseran horisontal observasi dan teoritis atau model.

Mengacu persamaan 5 dan 6 dengan mengambil nilai $k$ sebagai nilai intensitas yang mewakili besarnya jari-jari dan tekanan hidrostatik serta korelasinya terhadap rigiditas medium. Penyederhanaan kedua persamaan tersebut, sehingga menjadi persamaan 2.6 dan 2.7 dengan keterangan notasi seperti pada persamaan

$$
\Delta d=k \frac{d}{\left(\mathbf{f}^{2}+d^{2}\right)^{2}}
$$




$$
\begin{aligned}
& \Delta h=k \frac{f}{\left.\mathbb{f}^{2}+d^{2}\right)} \\
& k=\frac{3 a^{3} \Delta \mathrm{P}}{4 \mu}
\end{aligned}
$$

Skema perubahan posisi dua buah titik pengamatan $A \varangle_{a}, y_{a}, z_{a}$ - dan $B \varangle_{b}, y_{b}, z_{b_{-}}$ akibat adanya tekanan pada $P \ll, y, z$, ditunjukkan pada Gambar 3.7. Perubahan posisi tersebut $A^{\prime} \mathbb{C}_{a}^{\prime}, y_{a}^{\prime}, z_{a}^{\prime}{ }_{-}^{-}$dan $B^{\prime} \mathbb{\leftarrow}_{b}^{\prime}, y_{b}^{\prime}, z_{b}^{\prime}$ menyebabkan perubahan jarak miring di antara kedua titik dari $L$ menjadi $L^{\prime}$ sebesar $\Delta L$.

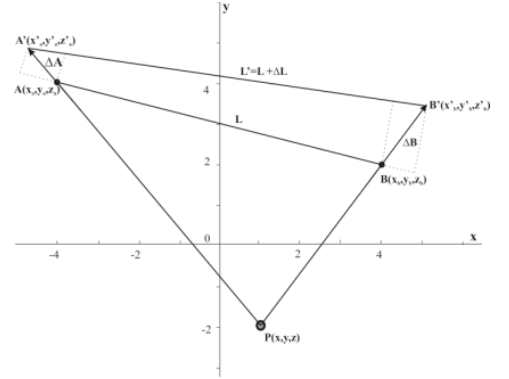

Gambar 3.7 Skema perubahan jarak miring akibat (Iguchi, 2011)

Jarak horisontal suatu stasiun navigasi $B$ (Gambar 3.7) terhadap sumber tekanan yang terletak di $\&, y, z^{-}$digambarkan dalam persamaan 3.10. Pergeseran pada stasiun $B$ merupakan nilai pergeseran relatif terhadap stasiun referensi, sebagai contah pada Gambar 2.16 adalah $A$. Diakibatkan oleh data observasi dengan metoda GPS memberikan akurasi yang lebih presisi pada komponen horisontal, maka digunakan nilai pergeseran horisontal dan mengabaikan pergeseran vertikal. Selanjutnya melalui persamaan 3.10 dan 3.11, pergeseran horisontal dapat dihitung secara teoritis. Dalam hal ini posisi sumber tekanan diasumsikan di bawah crater.

$$
d=\sqrt{4_{b}-x_{s}^{2}+\alpha_{b}-y_{s}^{2}}
$$

$$
\Delta d_{\text {teoritis }, b}=\Delta d_{b}-\Delta d_{a}
$$

\begin{tabular}{|c|c|}
\hline$d$ & $\begin{array}{l}\text { Jarak antara stasiun navigasi terhadap } \\
\text { terhadap crater }\end{array}$ \\
\hline$l_{b}$ & $\begin{array}{l}\text { : Jarak antara stasiun navigasi } B \text { terhadap } \\
\quad \text { terhadap crater }\end{array}$ \\
\hline$d_{a}$ & $\begin{array}{l}\text { Jarak antara stasiun referensi } A \text { terhadap } \\
\text { terhadap crater }\end{array}$ \\
\hline & : Kedalaman sumber tekanan \\
\hline${ }_{b}, y_{b}$ & Posisi bujur dan lintang stasiun navigasi \\
\hline$s, y_{s}$ & : Posisi bujur dan lintang crater \\
\hline$y_{a}$ & : Posisi bujur dan lintang stasiun referensi \\
\hline${ }_{b}, e_{a}$ & $\begin{array}{l}\text { Vektor satuan dari sumber ke stasiun } \\
\text { navigasi } B \text { dan stasiun referensi } A\end{array}$ \\
\hline$\Delta d_{a}$ & : Pergeseran horisontal di stasiun referensi \\
\hline$\Delta d_{b}$ & : Pergeseran horisontal di stasiun navigasi $B$ \\
\hline 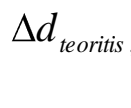 & $\begin{array}{l}s, b \text { : Pergeseran horisontal teoritis di stasiun } \\
\text { navigasi } B\end{array}$ \\
\hline
\end{tabular}

$$
=k\left[\frac{d_{b}}{\mathbf{d}_{b}^{2}+f^{2} \boldsymbol{J} 2} e_{b}-\frac{d_{a}}{\mathbf{d}_{a}^{2}+f^{2} \boldsymbol{J}^{2}} e_{a}\right]
$$

Keterangan:

Dalam pemodelan sumber tekanan dengan geometri bola (Mogi), nilai intensitas $k$ ditentukan melalui metoda grid search antara perubahan horisontal model dan observasi hingga diperoleh nilai kuadrat terkecil atau resultan a dan b bernilai $1 . k$ awal diasumsikan dari volume rata-rata yang dikeluarkan oleh suatu proses erupsi. Dalam hal ini $k$ awal adalah $10^{7}$ yang merupakan volume rata-rata erupsi Gunung Merapi dengan VEI 2. Nilai input kedalaman yang dilakukan secara trial and error pada penelitian ini dilakukan dengan range 2 meter sebanyak 20000x iterasi. Jika Resultan dari a dan b telah bernilai 1, maka looping/iterasi secara otomatis akan berhenti karena nilai konstanta $\mathrm{K}$ terbaik didapat pada saat resultan a dan $\mathrm{b}$ bernilai 1.Iterasi pertama dilakukan dengan memasukkan $k$ awal dan kedalaman bervariasi dari 0 hingga $20 \mathrm{~km}$. 
Tabel 2. Parameter metoda grid search Model (BPPTKG,2013)

\begin{tabular}{|c|c|c|}
\hline Parameter & Range & Iterasi \\
\hline Bujur & $110,4323244-110,4646846$ & 20000 \\
\hline Lintang & $7,521613206-7,567797353$ & 20000 \\
\hline Kedalaman & $-20000 m$ & 20000 \\
\hline Intensitas & $10^{6}-10^{7} \mathrm{~m}^{3}$ & 20000 \\
\hline
\end{tabular}

Tabel 3. Hasil prediksi sumber magma tekanan Gunung Merapi menggunakan program MOGI.

\begin{tabular}{lr}
\hline Nilai K & 9997231.482 \\
\hline Nilai Kedalaman & $7140.5084 \mathrm{~m}$ \\
Lintang & -7.5339 \\
Bujur & 110.4476 \\
Volume supply magma & $41788427.5957 \mathrm{~m}^{3}$
\end{tabular}

Dengan memasukkan nilai awal dari setiap parameter di atas ke dalam program Mogi, akan didapatkan nilai konstanta $k$ yang sebenarnya yang kemudian disubtitusi sehingga didapat nilai kedalaman terbaik terhadap 3 titik pengamatan.

\section{PENUTUP}

Berdasarkan hasil analisis penelitian tugas akhir yang telah dilakukan maka dapat diambil kesimpulan sebagai berikut :

1. Arah pergeseran pada bulan September 2013 - Maret 2014 menunjukan arah yaitu GPS DELS menuju ke arah barat daya, GPS GRWH menuju ke arah barat daya, dan GPS KLAT menuju ke arah selatan.Berdasarkan titik ikat BPTK, Gunung Merapi pada bulan September 2013-Maret 2014 terjadi inflasi dengan pergeseran titik pengamatan GPS DELS sebesar $0.026008793 \mathrm{~m}$ GPS KLAT sebesar 0.061873704 mdan GPS GRWH sebesar $0.019806277 \mathrm{~m}$.
2. Sumber tekanan magma berada di koordinat $7^{\circ} 32^{\prime} 2.129^{\prime \prime}$ LS ; $110^{\circ} 26^{\prime} 51.57^{\prime}$ BTdengan kedalaman $7140.5048 \mathrm{~m}$ dibawah puncak Gunung Merapi. Dari penilitan tugas akhir ini, kondisi Gunung Merapi dikatakan masih dalam fase normal walaupun telah terjadi inflasi dari pengolahan dengan titik ikat BPTK pada bulan September 2013-Maret 2014.

\section{DAFTAR PUSTAKA}

Abidin, H.Z. 2007. Penentuan Posisi dengan GPS dan Aplikasinya. Jakarta : PT Pradnya Paramita.

Bahlefi,Andika Rizal. 2013. Analisis Deformasi Gunung Merapi Tahun 2012 Dari Data Pengamatan GPS. Program Studi Teknik Geodesi.Universitas Diponegoro.

BPPTKG. Balai Penyelidikan dan Pengembangan Teknologi Kebencanaan Geologi. Sejarah Merapi.

www.merapi.bgl.esdm.go.id/informasidi akses pada tanggal 25 Januari 2014 pada pukul 20.34 WIB

Iguchi, M., Takayam, T., Yamazaki, T., Tada, M., and Suzuki, 2011, Movement of Magma at Sakurajima Volcano Revealed by GPS Observation. Ann. Disast. Prev. Res. Inst. Kyoto University., 51B, 241-246.

Jamel, Ilham. 2012. Analisis Deformasi Gunung berapi Papandayan Berdasarkan Data Pengamatan GPS Tahun 2002 - 2011. Tugas Akhir Program Studi Teknik Geodesi dan Geomatika.ITB

Syahputra, Reyzansza Anandio. 2014. Pemodelan Deformasi Dari Data GPS untuk Penentuan Lokasi Pusat Tekanan Magma Kawasan Vulkanik Aktif Menggunakan Model Mogi. Tugas Akhir Program Studi Teknik Geomatika ITS.

Wolf, Paul R dan D. Ghilani, Charles. 2006. Adjustment Computations Spatial Data Analysis. New Jersey : John Wiley \& Sons, Inc. 